\title{
A review of control processes and their locus in language switching
}

\author{
Mathieu Declerck $^{1,2}$ • Andrea M. Philipp ${ }^{1}$
}

Published online: 28 April 2015

(C) Psychonomic Society, Inc. 2015

\begin{abstract}
Language switching has been one of the main tasks to investigate language control, a process that restricts bilingual language processing to the target language. In the current review, we discuss the How (i.e., mechanisms) and Where (i.e., locus of these mechanisms) of language control in language switching. As regards the mechanisms of language control, we describe several empirical markers of language switching and their relation to inhibition, as a potentially important mechanism of language control. From this overview it becomes apparent that some, but not all, markers indicate the occurrence of inhibition during language switching and, thus, language control. In a second part, we turn to the potential locus of language control and the role of different processing stages (concept level, lemma level, phonology, orthography, and outside language processing). Previous studies provide evidence for the employment of several of these processing stages during language control so that either a complex control mechanism involving different processing stages and/or multiple loci of language control have to be assumed. Based on the discussed results, several established and new theoretical avenues are considered.
\end{abstract}

Keywords Speech production · Language comprehension . Task switching or executive control

Mathieu Declerck

mathieu.declerck@blri.fr

1 Institute of Psychology, RWTH Aachen University, Aachen, Germany

2 Laboratoire de Psychologie Cognitive, Brain \& Language Research Institute, Aix-Marseille University, Marseille, France
When bilinguals process language, words from the non-target language can be activated, and sometimes even selected by mistake (e.g., Costa, Caramazza, \& Sebastián-Gallés, 2000; Gollan, Sandoval, \& Salmon, 2011; Hermans, Bongaerts, De Bot, \& Schreuder, 1998). Therefore, it is crucial to restrict bilingual language production to the target language and to reduce between-language interference during bilingual language comprehension. This restriction process, called language control, appears to be very effective because very few non-target language words get selected during bilingual language production (e.g., Gollan et al., 2011; Poulisse \& Bongaerts, 1994). One commonly used task to investigate the underlying mechanism of language control is language switching.

Language switching measures have been investigated for several decades (e.g., Kolers, 1966; Macnamara, Krauthammer, \& Bolgar, 1968; Macnamara \& Kushnir, 1971) in behavioral studies (e.g., Costa \& Santesteban, 2004; Finkbeiner, Almeida, Janssen, \& Caramazza, 2006; Guo, Liu, Chen, \& Li, 2013), electrophysiological studies (e.g., Chauncey, Grainger, \& Holcomb, 2011; Jackson, Swainson, Mullin, Cunnington, \& Jackson, 2004; Verhoef, Roelofs, \& Chwilla, 2010), neuroimaging studies (e.g., Hernandez, Dapretto, Mazziotta, \& Bookheimer, 2001; Hosoda, Hanakawa, Nariai, Ohno, \& Honda, 2012; Price, Green, \& von Studnitz, 1999), and patient studies (e.g., Abutalebi, Miozzo, \& Cappa, 2000; Calabria, Marne, RomeroPinel, Juncadella, \& Costa, 2014). These studies encompass both bilingual comprehension (e.g., Grainger \& Beauvillain, 1987; Orfanidou \& Sumner, 2005; von Studnitz \& Green, 1997) and bilingual production (e.g., Festman, Rodriguez-Fornells, \& Münte, 2010; Linck, Schwieter, \& Sunderman, 2012; Meuter \& Allport, 1999) with children (Jia, Kohnert, Collado, \& Aquino-Garcia, 2006; Kohnert, 2002; Kohnert, Bates, \& Hernandez, 1999), young adults (e.g., Christoffels, Firk, \& 
Schiller, 2007; Prior \& MacWhinney, 2010; Tarlowski, Wodniecka, \& Marzecová, 2013), and older adults (e.g., Calabria, Marne, et al., 2015; Hernandez \& Kohnert, 1999; Weissberger, Wierenga, Bondi, \& Gollan, 2012).

In this review, we aimed to cover how language control operates in language switching and discuss the role of different processing stages (concept level, lemma level, phonology, orthography, and outside language processing) during language control in language switching. The main focus for both these issues is on behavioral results (for nonbehavioral language switching reviews, see Abutalebi \& Green, 2007, 2008; Luk, Green, Abutalebi, \& Grady, 2012) and how these relate to models of language control.

\section{Language switching paradigms}

Over the years, several distinct language switching paradigms have been developed that differ in terms of implementing specific concepts and/or languages (see Fig. 1 for examples of each paradigm).
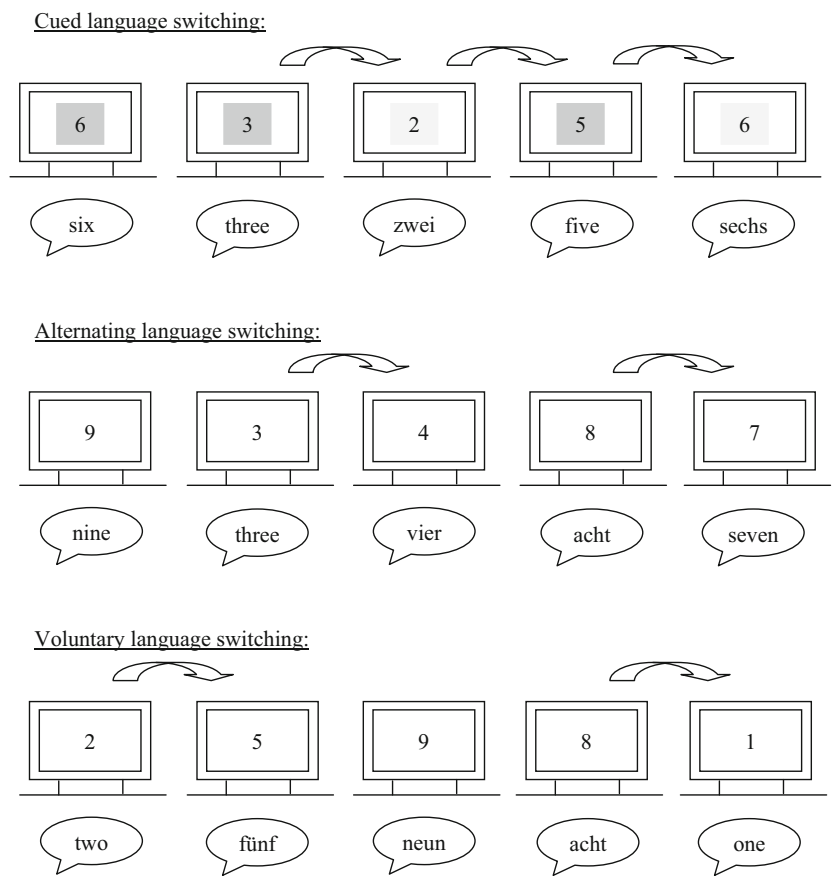

Sequence-based language switching:

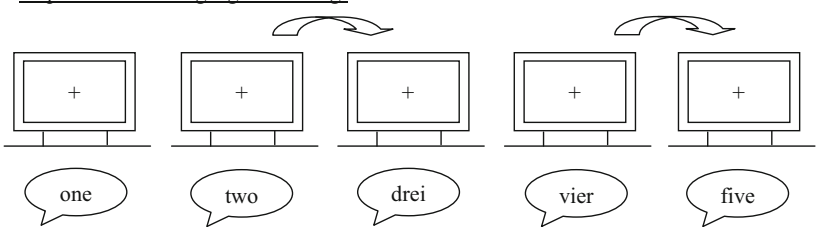

Fig. 1 Examples of the experimental set-up of cued language switching, alternating language switching, voluntary language switching, and sequence-based language switching. Note. Arrows refer to switch trials, and differently shaded backgrounds refer to different language cues

\section{Cued language switching}

The cued language switching paradigm is the most commonly used paradigm in the language switching literature. Typical for this paradigm is the presentation of visual digits or pictures to specify the concepts that need to be named. Because multiple (usually two) languages are implemented in language switching, visual language cues are used to indicate in which language the concepts need to be produced. This procedure indicates that such a paradigm has mainly been implemented in production studies because comprehension studies generally use written words (e.g., Orfanidou \& Sumner, 2005; Thomas \& Allport, 2000). These words already inherently contain information about the required target language, thus eliminating the need for an additional, explicit visual cue.

An example of cued language switching can be found in the seminal paper of Meuter and Allport (1999), in which the bilinguals (languages varying from English, French, German, Italian, Portuguese, and Spanish) were presented with digits, to indicate the required concept, and colored rectangles (blue and yellow), to indicate the required language. Their task consisted of naming the digits according to the corresponding language of the language cue.

Because of the use of two languages within a block, bilinguals had to either switch from one language to another (switch trials) or repeat the same language as the prior trial (repetition trials). Next to Meuter and Allport (1999), an abundance of studies have observed worse performance in switch trials relative to performance in repetition trials (e.g., Costa \& Santesteban, 2004; Christoffels et al., 2007; Philipp, Gade, \& Koch, 2007; Verhoef, Roelofs, \& Chwilla, 2009). This difference between trial types has been termed "switch costs."

Performance in these mixed language blocks can also be contrasted against performance in pure language blocks, where bilinguals only have to name concepts in one language. A multitude of studies have shown that performance is worse in mixed language blocks than in pure language blocks (e.g., Christoffels et al., 2007; Gollan \& Ferreira, 2009; Hernandez \& Kohnert, 1999; Prior \& Gollan, 2013; Wang, Kuhl, Chen, \& Dong, 2009). This performance difference in pure and mixed language blocks has been labeled "mixing costs." To clearly differentiate between mixing costs and switch costs, trials in pure language blocks are usually compared to repetition trials of mixed language blocks (cf. Los, 1996).

Switch costs and mixing costs are assumed to measure different aspects of language control. Switch costs are considered to be a marker of transient, trial-to-trial control processes, whereas mixing costs are considered to be a marker of sustained control processes, reflecting a relatively global consequence of between-language interference (e.g., Christoffels et al., 2007; for a review, see Kiesel et al., 2010). Accordingly, evidence for differential influences on language switch costs 
and language mixing costs has been observed in several studies. These studies have shown that whereas either switch costs or mixing costs are larger for first language (L1) than second language (L2) costs, such a language difference does not occur for the other marker (Christoffels et al., 2007; Declerck, Philipp, \& Koch, 2013; de Bruin, Roelofs, Dijkstra, \& FitzPatrick, 2014; Gollan \& Ferreira, 2009; Wang et al., 2009).

\section{Alternating language switching}

Switch costs can also be observed when languages follow a predictable sequence (e.g., Festman et al., 2010; Jackson, Swainson, Mullin, Cunnington, \& Jackson, 2001). This is the case in the alternating language switching paradigm, during which bilinguals generally have to switch languages after every second trial (e.g., L1-L1-L2-L2-L1-L1, etc.). Jackson et al. (2001), for instance, observed switch costs when native English participants named digits in English (L1) or their L2 (French, German, Spanish, Mandarin, or Urdu). The language changed on every second trial and was accompanied by a redundant visual language cue (i.e., red and green or yellow and blue). However, switch costs can also be observed in an alternating language switching paradigm without redundant cues (e.g., Declerck, Stephan, Koch, \& Philipp, 2015b).

Similarly, switch costs were observed with a comprehension study by Jackson et al. (2004). In this study, bilinguals had to perform a parity task, by means of button presses, with written number words presented in their L1 (English) or L2 (French, German, or Spanish). Unlike the production version, however, no additional language cues accompanied the alternating language sequence, since the language information was already incorporated in the written words.

\section{Voluntary language switching}

Switch costs can even be found without an explicitly instructed language sequence, as can be observed with the voluntary language switching paradigm (Gollan \& Ferreira, 2009; Gollan, Kleinman, \& Wierenga, 2014). In this paradigm, bilinguals can choose when to switch to another language. More specifically, Gollan and Ferreira (2009) asked English-Spanish bilinguals to name pictures in whichever language they wanted (Experiments 1 and 3). The results showed that switch costs can be observed when bilinguals could freely choose whichever language they wanted to produce in. Yet, no switch costs were found when bilinguals were explicitly instructed to use both languages in $50 \%$ of the trials (Experiment 2). Moreover, in this condition there was even a trend towards a switch benefit.

Voluntary mixing costs were only found for L1 in all experiments, while the pattern for L2 was diverse, including a mixing benefit for second language learners but not for balanced bilinguals. According to Gollan and Ferreira (2009), this was due to second language learners mainly switching to L2 when naming simpler words, whereas they would switch back to L1 when presented with more challenging words.

In a more recent voluntary language switching study, Gollan, Kleinman, et al. (2014) also observed no switch costs. Yet, this was restricted to bilinguals that were assumed to let the pictures guide their choice of language (i.e., bottomuppers). Bilinguals who did not let the pictures guide them, but directed language selection by choice (i.e., top-downers), did show voluntary language switch costs.

\section{Sequence-based language switching}

While no visual language cues are necessary in alternating language switching and are not even implemented with voluntary language switching, no visual language cues AND stimuli are presented in the sequence-based language switching (SBLS) paradigm (e.g., Declerck, Koch, \& Philipp, 2015a; Declerck et al., 2013). To produce the required language and concept, bilinguals memorize a sequence for both. More specifically, the languages follow an alternating language sequence without any visual cues and the concepts follow a specific sequential order. In Declerck et al. (2013), this concept sequence consisted of overlearned sequences (i.e., weekdays or numbers) or newly learned sequences. Since no visual indication is given on when the bilinguals have to respond, they hear an auditory response-signal to indicate that they should produce one of the concepts in the target language. This results in the following possible sequence with numbers 1-5 when switching between German and English: eins (meaning one in German), zwei (meaning two in German), three, four, fünf (meaning five in German), eins, two, etc. Even though upcoming responses can be prepared, since they are completely predictable, both switch costs and mixing costs have been observed with this paradigm (Declerck et al., 2013, 2015a).

\section{Advantages of each paradigm}

From these different paradigms we can extrapolate that, regardless of whether language cues or stimuli are presented, switching languages usually contains a performance cost (i.e., switch costs and/or mixing costs). Thus, we conclude that performance costs in experimental language switching are a common empirical observation in all variants of language switching, with the exception of voluntary language switching under certain circumstances (Gollan \& Ferreira, 2009; Gollan, Kleinman, et al., 2014). Next to this commonality, each paradigm comes with its own advantages and disadvantages. 
The cued language switching paradigm, for example, can rely on a large amount and variety of research on language switching in language production tasks (as comprehension tasks usually do not implement cues, research is much more limited in this domain). Hence, we have extensive knowledge of the effects and processes at work during cued language switching.

Another advantage of the cued language switching paradigm are the modifications of several time-based intervals, such as the cue-to-stimulus interval, which is assumed to measure active language preparation, and the response-to-cue interval, which is assumed to measure passive decay (e.g., Kiesel et al., 2010). These time-based intervals cannot be manipulated as easily in the other language switching paradigms.

The alternating language switching paradigm allows for language preplanning, as the bilingual knows when switching to another language will occur, which is similar to preplanning during natural language production. Hence, he or she could prepare for the upcoming language based on the predictable sequence.

Even closer to natural language switching in this respect is the voluntary language switching paradigm because it does not rely on exogenous language cues but on endogenous (i.e., internal) language cues and thus also allows for language preplanning. Additionally, the voluntary language switching paradigm allows for other measures, namely when and how often bilinguals will switch between languages. These additional measures could give us more insight into the mechanism of language control during language switching.

Finally, the SBLS paradigm also allows for sequential predictability of language control. Yet, whereas this is restricted to language predictability in the alternating language switching and voluntary language switching paradigms, it encompasses the entire word in the SBLS paradigm. Another advantage of this paradigm is that all word categories can be investigated, since the memory-based concept sequence allows for a large variety of words. Yet, this is also possible with other paradigms when they employ written words.

Taken together, a large variety of language switching paradigms with individual strengths and weaknesses can be used to study language control in language switching. The common idea of all of the paradigms is that they allow researchers to explore how language control operates and which processes play a crucial role in language switching.

\section{To inhibit or not to inhibit}

One of the major topics regarding the mechanisms of language control in the language switching literature is inhibition (for a review on inhibition during bilingual language processing, see Kroll, Bobb, Misra, \& Guo, 2008), which entails the reduction of non-target language activation and thus interference resolution. This focus on inhibitory processes is also evident in the large amount of models that proposed language control to mainly rely on inhibition.

\section{Models of language control}

An influential model of language control is the inhibitory control model (ICM; Green, 1998), which explains switch costs with the notion of persisting inhibition: when on a trial (trial n1) a certain language has to be produced, the non-target language will be inhibited. In turn, when the previously inhibited language is required for production on the next trial (trial n; i.e., switch trial), the inhibition that was exercised on trial n-1 will persist into trial $\mathrm{n}$ and thus will have to be overcome. This is not the case when producing in the same language on trial $n-1$ and trial n (i.e., repetition trial). So, it should be harder to switch between languages than repeating the same language because persisting inhibition has to be overcome in switch trials. Green also assumed that the inhibitory process is reactive, meaning that a larger activation will lead to more inhibition.

Whereas the ICM is more production-based, the bilingual interactive activation model (BIA; Grainger \& Dijkstra, 1992), and later variants of this model, such as the BIA+ (Dijkstra \& van Heuven, 2002) or the BIA-d (Grainger, Midgley, \& Holcomb, 2010), focused on comprehensionbased language control. This model can account for switch costs by bottom-up activation of word representations to language nodes, which are mental language representations, and top-down inhibition of the irrelevant and, thus, competing language (node). During a switch trial another language node needs to be activated, and in turn interferes with processing, whereas during repetition trials the same language node is activated and thus processing can occur without language interference. Consequently, switch costs should occur.

Next to these inhibition-based models there are also language control models that do not rely on inhibition (e.g., Costa, Miozzo, \& Caramazza, 1999; Finkbeiner et al., 2006; La Heij, 2005; Roelofs, 1998). La Heij (2005), for example, proposed that a language representation of the target language receives additional activation from a corresponding language cue, thus making inhibition redundant.

While the latter models propose that no inhibition occurs during language switching, inhibition has been suggested as an explanation for several language switching measures, such as asymmetrical switch costs, n-2 language repetition costs, and reversed language proficiency in mixed language blocks. In the following subsections we will discuss these markers and their relation to inhibition.

\section{Asymmetrical switch costs as a marker for inhibition}

When searching for empirical evidence in favor of inhibition, most researchers turn to the occurrence of asymmetrical 
switch costs. This refers to switch costs being larger when switching into L1 than when switching into L2 (e.g., Jin, Zhang, \& Li, 2014; Macizo, Bajo, \& Paolieri, 2012; Meuter \& Allport, 1999; Philipp et al., 2007; Peeters, Runnqvist, Bertrand, \& Grainger, 2014; Verhoef et al., 2009; for a review, see Bobb \& Wodniecka, 2013). The most prevalent explanation of this effect is based on the ICM (Green, 1998), which assumes reactive, persisting inhibition to occur during language control. This explanation entails that, since L1 initially has a larger activation than L2, more inhibition will be needed to suppress L1 during L2 production than vice versa (cf. reactive inhibition). In turn, this will lead to larger persisting inhibition on L1 than on L2, which should lead to larger switch costs when switching into L1 than when switching into L2.

Some evidence has been accumulated that asymmetrical switch costs are related to inhibition. For example, Linck et al. (2012) and Liu, Rossi, Zhou, and Chen (2014) have shown that asymmetrical switch costs are, at least partially, related to inhibition, as measured by the Simon task (Simon, 1969). Yet, there are also arguments against using asymmetrical switch costs as a marker for inhibition.

Universality of asymmetrical switch costs A first concern is that several studies did not find asymmetrical switch costs (e.g., Christoffels et al., 2007; Verhoef et al., 2010; for reversed asymmetrical switch costs, see Declerck, Stephan, et al., 2015b), an observation that has also been found in task switching (for a review, see Koch, Gade, Schuch, \& Philipp, 2010). This is especially marked in comprehension studies, where typically no asymmetrical switch costs are observed (e.g., Macizo et al., 2012; Thomas \& Allport, 2000). Furthermore, symmetrical switch costs are usually observed with highly proficient bilinguals in production tasks (e.g., Costa \& Santesteban, 2004; Costa, Santesteban, \& Ivanova, et al., 2006). This finding is conceived as evidence that highly proficient bilinguals do not use inhibition during language control (for a more detailed discussion on highly proficient bilinguals and inhibition see below). Hence, asymmetrical switch costs seem to depend on the type of task and on the bilinguals.

Language dominance and naming speed A second concern for assuming that asymmetrical switch costs are a marker for inhibition refers to the relation of language dominance in overall naming speed and asymmetrical switch costs. More specifically, if asymmetrical switch costs depend on higher L1 activation than L2 activation (cf. Green, 1998), one would expect faster naming of L1 words than L2 words when asymmetrical switch costs are observed. Some studies have shown exactly this pattern of faster overall L1 than L2 naming and asymmetrical switch costs (e.g., Linck et al., 2012; Macizo et al., 2012). However, there have also been studies that found faster overall L1 than L2 naming and symmetrical switch costs (e.g., Declerck, Koch, \& Philipp, 2012; Declerck et al., 2015a; see also de Bruin et al., 2014). Moreover, faster overall L2 than L1 naming has been observed with both symmetrical switch costs (e.g., Christoffels et al., 2007; Gollan \& Ferreira, 2009; Verhoef et al., 2010) and asymmetrical switch costs (e.g., Costa \& Santesteban, 2004, Experiment 1; Verhoef et al., 2009), and similar overall L1 and L2 naming with asymmetrical switch costs (e.g., Declerck et al., 2013, Experiment 3; Filippi, Karaminis, \& Thomas, 2014) and symmetrical switch costs (Calabria et al., 2011; Fink \& Goldrick, 2015).

This unclear pattern raises some questions about the reactive inhibitory nature of language control in language switching. Yet, to reconcile the idea of reactive inhibition, language dominance and overall naming speed, one might suggest that language dominance influences the asymmetry of switch costs at an earlier processing stage in language processing than the overall naming speed is influenced (cf. Declerck, Thoma, Koch, \& Philipp, 2015c).

Different mechanisms to explain asymmetrical switch costs A final, more theoretical, concern is that asymmetrical switch costs can also be explained with mechanisms different from inhibition. For example, the notion of reactive activation (Philipp et al., 2007) entails that L2 requires a relatively larger amount of activation than L1 on trial $n-1$. This increase of activation will persist into trial $\mathrm{n}$, thus causing a more considerable competitor for L1 than L2 on switch trials. So, asymmetrical switch costs can be explained without the notion of inhibition, using a similar logic as Green (1998) proposed. ${ }^{1}$ Yet, this interpretation comes with similar concerns as the ICM.

A different interpretation of asymmetrical switch costs proposes that the initial response of switch trials can be rejected when these are too fast (Finkbeiner et al., 2006). This is meant to prevent errors, as switch trials are supposed to be difficult and thus no fast responses can be given in this difficult situation. Since L1 trials are more dominant, they are generally also easier and thus faster. Hence, more initial L1 switch responses will be rejected than $\mathrm{L} 2$ switch responses, leading to larger L1 than L2 switch costs.

This explanation is based on a monolingual experiment in which bilinguals had to name words that are generally produced fast or slow. The results showed that fast words elicit larger switch costs than slow words. However, as noted above, the overall naming speed in language switching experiments does not always show faster performance in L1 than L2 although switch costs were larger for L1 than L2 (e.g., Costa \& Santesteban, 2004; Verhoef et al., 2009). Hence, it is doubtful

\footnotetext{
${ }^{1}$ The notion of activation is not totally new to the ICM, which is seen as one of the biggest proponents of the inhibition account. One such example of activation in the ICM is between language schemas and their respective language nodes. Similarly, other models have also assumed some activation processes to occur (e.g., Declerck et al., 2015a; Grainger et al., 2010; Schwieter \& Sunderman, 2008).
} 
that faster production in one language leads to larger switch costs in that language.

The final account of asymmetrical switch costs was proposed by Verhoef et al. (2009). These authors speculated that the switch cost asymmetry across languages is due to a larger L1-repetition benefit than L2-repetition benefit. This interpretation comes from the assumption that interference of the nontarget language influences all trial types except L1 repetition trials, which are thus always the fastest. To test this hypothesis, Verhoef and colleagues investigated the effect of language preparation time on asymmetrical switch costs. More specifically, they manipulated the cue-to-stimulus interval, which allows for more (long interval) or less (short interval) language preparation. Their results showed that longer language preparation led to symmetrical switch costs with DutchEnglish bilinguals, whereas short language preparation led to asymmetrical switch costs. Furthermore, they found that all trials benefited from longer language preparation time, apart from L1-repetition trials. The latter finding is an indication that all trial types, apart from the L1-repetition trials, suffer from language interference.

Yet, no preparation-based difference in asymmetrical switch costs was found in other language switching studies that investigated the effect of language preparation (Costa \& Santesteban, 2004; Declerck et al., 2015a; Fink \& Goldrick, 2015; Philipp et al., 2007). Furthermore, Fink and Goldrick (2015) also looked into the effect of language preparation time on L1 repetition trials. According to Verhoef et al. (2009) these types of trials should be unaffected by language preparation. In contrast, Fink and Goldrick (2015) observed a preparation benefit for these trials. Taken together, the lack of replication of Verhoef et al.'s (2009) behavioral findings seems to put into question the idea that L1 repetition trials are not affected by language interference. Consequently, the idea of an L1-repetition benefit to explain asymmetrical switch costs should be reexamined.

Taken together, there are several different explanations to account for the switch cost asymmetry, but each of these explanations seems to fall short to account for the observed language switching data. This begs the question of what asymmetrical switch costs really measure. Philipp et al. (2007) have argued that asymmetrical switch costs could be explained by more than one process. Specifically, they argued that a combination of persisting activation and a small role for persisting inhibition could explain most results. We concur with the idea that asymmetrical switch costs might be the sum of more than one process and thus not an ideal measure for solely persisting, reactive inhibition.

\section{N-2 language repetition costs as a marker for inhibition}

A less ambiguous marker for inhibition are n-2 language repetition costs (Declerck, Thoma, et al., 2015c; Guo et al., 2013a, b; Philipp et al., 2007; Philipp \& Koch, 2009). Unlike the previous markers, n-2 language repetition costs require three languages to be measured. Consequently, performance on language $\mathrm{A}$ is measured in $\mathrm{CB} A$ and $\mathrm{AB} A$ sequences, with " $\mathrm{A}$," "B," and "C" being trials with different languages. The results typically show that performance is worse on $\mathrm{AB} A$ sequences than on $\mathrm{CB} A$ sequences. This performance difference is explained by assuming that in each trial the non-target languages become inhibited to produce in the target language. Inhibition hereby is reactive depending on the activation of a non-target language, which is based on language dominance (cf. Green, 1998) and recency of language use (i.e. the language used in the preceding trial is activated to a relatively high degree and, thus, inhibited to a high degree; that is producing language $\mathrm{B}$ in an $\mathrm{AB} A$ sequence leads to a strong inhibition of language $\mathrm{A})$. As the inhibition persists, it will be stronger when producing in the same language as two trials prior to the current trial $(\mathrm{AB} A)$, relative to having produced in that language with a longer interval $(\mathrm{CB} A)$.

Unlike asymmetrical switch costs, n-2 language repetition costs cannot be explained by persisting activation, since an opposite pattern would be observed (i.e., n-2 language repetition benefit). Further, up to now, there is no alternative explanation for $n-2$ language repetition costs (for a review of $\mathrm{n}-2$ repetition costs in task switching, see Koch et al., 2010), which makes this a less ambiguous marker for the notion of inhibition in language switching.

Yet, similar to switch costs, the specific pattern of n-2 repetition costs across languages is not consistent. Both Philipp et al. (2007) and Guo et al. (2013a, Experiment 1) observed an asymmetry of n-2 language repetition costs across languages with larger L1 n-2 language repetition costs than with L3. However, no such effect was observed in the second Experiment of Guo and colleagues and in either experiment of Philipp and Koch (2009). Furthermore, only Philipp et al. (2007) observed larger L1 n-2 language repetition costs than with L2. Moreover, while Guo and colleagues (Experiments 1 and 2) found larger L2 n-2 language repetition costs than with L3, Philipp et al. (2007) found an opposite effect. This mixed data pattern does not speak against persisting inhibition as n-2 repetition costs were consistently found. Yet, we suppose that this data pattern indicates that there are multiple influences on language activation (e.g., language dominance, recency of language use,...) and its relation to inhibition. Moreover, the complexity of the data pattern might also indicate that different loci of inhibition could play a role (e.g., Bobb \& Wodniecka, 2013; Gollan, Schotter, Gomez, Murillo, \& Rayner, 2014; Kroll, Bobb, \& Wodniecka, 2006), and that the involvement of specific loci is dependent on the level of language activation. Consequently, different patterns of performance costs can be observed across languages in different studies due to differences in language activation. 


\section{When L2 outperforms L1}

The inhibitory mechanism discussed so far relates to the assumption of a short-termed, trial-based inhibitory process. However, inhibition is not necessarily restricted to a single mechanism. A different form of inhibition in language switching could be general inhibition of one language. Possible evidence for this type of inhibition has been found in mixed language blocks.

When comparing L1 and L2 performance in pure language blocks, L1 performance is typically better than L2 performance (e.g., Christoffels et al., 2007; for reviews, see, Hanulová, Davidson, \& Indefrey, 2011; Runnqvist, Strijkers, Sadat, \& Costa, 2011). This has generally been explained with a larger L1 activation than L2 activation. Whereas such a pattern has also been observed in several studies using mixed language blocks (e.g., de Bruin et al., 2014; Linck et al., 2012; Macizo et al., 2012), there are also studies that observed worse L1 performance than L2 performance in mixed language blocks (e.g., Christoffels et al., 2007; Costa \& Santesteban, 2004; Gollan \& Ferreira, 2009; Verhoef et al., 2009, 2010). Interestingly, this is only the case in production studies, while comprehension studies do not show this pattern (similar to asymmetrical switch costs).

According to Costa and Santesteban (2004), this reversal could be due to bilinguals facilitating production in both languages by generating more equal activation levels across languages. More specifically, Costa and Santesteban assumed that the selection criteria of each language can be altered independently from the selection criteria of other languages. Consequently, by changing the selection criteria, a difference in overall language performance could be observed. Alternatively, the activation level of the two languages might be equalized by a constant inhibition of L1 throughout mixed language blocks (see also Gollan \& Ferreira, 2009) or increased activation of L2 throughout mixed language blocks (Declerck, Thoma, et al., 2015c).

Hence, overall increased performance of L2 over L1 in mixed language blocks can be explained with a global inhibition of L1. However, other explanations, such as a global increase of L2 activation or a difference in selection criteria across languages, are also possible, making it not an ideal marker for inhibition.

\section{Highly proficient bilinguals vs. second language learners}

The empirical evidence discussed so far refers to a specific group of bilinguals, namely second language learners with a clearly dominant L1 and a less dominant L2. This specification is theoretically important because several models have assumed that, contrary to second language learners, highly proficient bilinguals require very little to no inhibition (Costa \& Santesteban, 2004; Schwieter \& Sunderman,
2008). The selection by proficiency model of Schwieter and Sunderman (2008), for example, assumes that language control occurs similarly as the ICM for second language learners, but not for highly proficient bilinguals (see also Costa \& Santesteban, 2004). In this model, highly proficient bilinguals rely on language cues, which posit the target language at the concept stage (see also La Heij, 2005). These language cues make sure that more activation will go to the target representation than to the translation-equivalent non-target representation. In turn, no inhibition is required between languagespecific representations for highly proficient bilinguals.

The assumption of different language control processes due to language proficiency is mainly based on a lack of asymmetrical switch costs with highly proficient bilinguals (e.g., Calabria et al., 2011; Costa \& Santesteban, 2004; Costa, Santesteban, et al., 2006; Christoffels et al., 2007; Martin et al., 2013; Meuter \& Allport, 1999). These symmetrical switch costs across languages were first observed by Meuter and Allport (1999), who investigated the influence of language proficiency on switch costs by splitting their participants into highly proficient bilinguals and second language learners. Their results indicated that asymmetrical switch costs are indeed dependent on language proficiency, since the highly proficient group revealed symmetrical switch costs and the second language learners revealed asymmetrical switch costs.

This finding is in line with Filippi et al. (2014), who found that asymmetrical switch costs were negatively correlated with L2 proficiency in a word naming task, and Schwieter and Sunderman (2008), who found that switch costs get symmetrical at a certain L2 proficiency threshold (measured by verbal fluency). These studies indicate the importance of language proficiency in language switching and more specifically with regard to asymmetrical switch costs.

The observation of symmetrical switch costs with the two highly proficient languages could be interpreted with reactive, persisting inhibition, by assuming that the similarity in language activation will result in a similar amount of inhibition between the two languages and thus an equal amount of inhibition has to be overcome during switch trials. Consequently, similar switch costs could be observed across languages.

Yet, Costa and Santesteban (2004) and Costa, Santesteban, et al., (2006) even observed symmetrical switch costs when highly proficient Spanish-Catalan bilinguals switched between one of their highly proficient languages (Spanish or Catalan) and a less dominant L3 (English). Similarly, Martin et al. (2013) observed asymmetrical switch costs when second language learners switched between L1 (Spanish) and L3 (Catalan, with L2 being English) and symmetrical switch costs when highly proficient bilinguals switched between L1 (Spanish) and L3 (English, with L2 being Catalan). Martin et al. (2013) found more converging evidence by contrasting highly proficient bilinguals that switched between L1 (Spanish) and L3 (English, with L2 being Catalan) and highly 
proficient bilinguals that switched between L1 (Spanish) and L2 (Catalan, with L3 being English), since no difference was found in terms of (a)symmetrical switch costs between these two groups.

Symmetrical switch costs when switching between one of the highly proficient languages and a less dominant L3 does not comply with the logic of reactive, persisting inhibition, since the activation of the dominant language is far higher than that of the less dominant language. In turn, Costa and Santesteban (2004) argued that no inhibition is implemented during bilingual language control of highly proficient bilinguals. However, asymmetrical switch costs were found when highly proficient bilinguals produced an L4 (French) or a newly learned language (Costa, Santesteban, et al., 2006). These findings led to acknowledge that some inhibition might be required during bilingual language production of highly proficient bilinguals. Yet, this was only the case in very distinct contexts (see also Schwieter \& Sunderman, 2008).

Nevertheless, as mentioned above, it is still unclear whether asymmetrical switch costs should be taken as an unequivocal measure of inhibition at all. In a very recent study, highly proficient Turkish-German bilinguals were examined with n2 language repetition costs (Declerck, Thoma, et al., 2015c). These bilinguals were second generation Turkish emigrants that lived in Germany and thus were used to producing both Turkish and German on a daily basis. Next to the symmetrical switch costs obtained by letting them switch between Turkish and German, also n-2 language repetition costs were observed by letting them switch between Turkish, German, and English (L3). Moreover, larger n-2 language repetition costs were observed with Turkish and German than in English, whereas a similar amount of $n-2$ language repetition costs were elicited by Turkish and German. These results are completely in line with the notion of persisting, reactive inhibition (e.g., Green, 1998). They are not, however, in line with models that assume that highly proficient bilinguals implement no inhibition.

\section{Implications}

While not all measures that were discussed above provide unambiguous evidence for inhibition, there seems to be some evidence that inhibitory processes are at play during language switching (cf. n-2 language repetition costs). This evidence speaks in favor of both second language learners and highly proficient bilinguals relying on inhibitory processes in order to reduce between-language interference, which is in line with language control models that proposed a role for inhibition during language control (e.g., Declerck et al., 2015a; Dijkstra \& van Heuven, 2002; Grainger et al., 2010; Green, 1998). In turn, it provides evidence against models that do not assume so (e.g., Costa et al., 1999; Finkbeiner et al., 2006; Roelofs, 1998).
More specifically, the evidence seems to mainly support a dynamic trial-to-trial inhibitory process. This does not mean that other types of inhibitory processes, such as the proposed global inhibition that could explain overall better L2 performance than L1 performance in mixed language blocks, do not occur during language switching. The only problem is that, so far, this effect can be explained without inhibition, by assuming differences in selection criteria across languages or a global activation increase of L2.

This also leads to an important question — namely, whether solely inhibition is required for language control or whether other processes, such as activation (Philipp et al., 2007), also play an important role during language control. The implementation of several processes (e.g., inhibition and activation) during language switching could very well be the case even though evidence for inhibition has been found in language switching, because inhibition and activation are not mutually exclusive processes. These different types of language control processes could also occur at different processing stages of language processing (Bobb \& Wodniecka 2013; Gollan, Schotter, et al., 2014; Kroll et al., 2006). Regrettably, mainly inhibition has been used to explain language switching results, while other processes have been mostly ignored. So, at this point the involvement of processes other than inhibition remains unclear, making research into this field an important avenue for future research

\section{Role of different processing stages during language control}

The conclusion that bilingual language control appears to rely, at least partially, on inhibitory processes, is not specific to the question of what is inhibited in language control and when this inhibition occurs. Language processing, both in language production and language comprehension, entails different processing stages and each of these processing stages could play a crucial role for language control.

Spoken word production (e.g., Levelt, Roelofs, \& Meyer, 1999) starts with the formation of a nonlinguistic concept, at which stage the to-be-expressed information is formed. Next, syntactic information is included at the lemma level, followed by the addition of sound representations at the phonological level. Finally, articulation occurs, which involves activation of the necessary muscles.

During comprehension of written words, which are the typical stimuli used in comprehension-based language switching studies, the order is reversed (e.g., Grainger \& Holcomb, 2009; Plaut, McClelland, Seidenberg, \& Patterson, 1996), starting with encoding of visual stimuli. These stimuli activate the appropriate corresponding orthographic representations, which in turn trigger lemmas and concepts. 


\section{Functional locus (or loci) in models of language control}

According to language control models, several of the described processing stages could be a locus of language control. Yet, there seems to be a divide among these models with respect to the functional locus or loci that they propose. Some models assume that the functional locus of language control can be found at the concept level (La Heij, 2005; Poulisse \& Bongaerts, 1994; see also Schwieter \& Sunderman (2008) with highly proficient bilinguals). La Heij (2005), for example, assumed that language cues at the concept stage allow for additional activation of the target representation in the correct language. Consequently, target representations in the corresponding language should be selected.

Other models assume that the functional locus of language control can be found at the lemma level (Declerck et al., 2015a; Grainger et al., 2010; Green, 1998; see also Schwieter \& Sunderman (2008) with second language learners). In the modified ICM (Declerck et al., 2015a), bilingual language processing starts with the activation of language schemas, which are mental devices that are implemented to achieve task-specific goals, like speaking in a certain language. Once the lemmas have been activated by their respective concepts, each language schema activates their corresponding language node and an inhibitory competition process occurs between these language node(s). In turn, the language nodes inhibit lemmas of the other language. Finally, competition between the target lemma and the translationequivalent lemma results in selection. So, language control occurs between language nodes and between lemmas (both located at the lemma level) according to this model. Furthermore, this model also includes stronger connections from concepts to the respective L1 lemmas than from concepts to their respective L2 lemmas for second language learners (cf. Kroll \& Stewart, 1994; see also Schwieter \& Sunderman, 2008).

Since the modified ICM (Declerck et al., 2015a) is based on the original ICM (Green, 1998), a similar progression is assumed in the latter. The main difference is that language control is presumed to occur between language schemas and between lemmas, according to this model, instead of between language nodes and lemmas in the modified ICM. Interestingly, the schemas proposed to control for language interference are similar to those used for more general cognitive control according to the ICM. Hence, the ICM assumes that language control occurs at the lemma level and outside of language processing.

A similar differentiation with respect to the assumed locus of language control can also be found in language control models of comprehension. More specifically, the BIA (Grainger \& Dijkstra, 1992) and BIA-d (Grainger et al., 2010) assume no language control outside of language processing. According to the BIA (Grainger \& Dijkstra, 1992), upon presentation of a letter string, features at a certain position will be activated. In turn, these features will influence letters that incorporate these features while inhibiting letters that do not. The letters activate whole word representations in all languages that contain these letters in the correct position of the word while again inhibiting all other word representations. The activated word(s) inhibits all other word representations while also activating their respective language nodes. Finally, the language nodes inhibit all words that are not a member of that language.

In the BIA + (Dijkstra \& van Heuven, 2002), a similar process is proposed to occur during comprehension-based language control as in the BIA, with the most important distinction being the differentiation between the word identification system, which entails linguistic influences, and a task/decision system, which entails nonlinguistic task schema influences. The latter being a processing stage outside of language processing.

Thus, several loci of language control have been proposed, ranging from the concept level, lemma level, and a processing stage outside of language processing (i.e., cognitive control processes). Interestingly, several models have even proposed more than one locus of language control (Declerck et al., 2015a; Dijkstra \& van Heuven, 2002; Green, 1998), both within and outside of language processing. In the next sections we will discuss whether there is empirical evidence for any of these potential control loci, and some that have not yet been considered (i.e., phonology and orthography).

\section{The role of the concept level during language control}

Since several models of language control proposed an important role for the concept level (Declerck et al., 2015a; La Heij, 2005; Poulisse \& Bongaerts, 1994; Schwieter \& Sunderman, 2008), either by differently weighed connections to the corresponding lemmas or as a functional locus of language control, one would assume that manipulations on this level would affect language switching. Declerck et al. (2015a) found that concepts and concept activation can have an impact on switch costs. In this study, German-English bilinguals could prepare through predictable information for several aspects of language switching (i.e., language, concept, or both). When concepts could be prepared, smaller L1 switch costs were observed than when concepts could not be prepared, whereas the effect of concept preparation on L2 switch costs was much smaller. This finding was explained by a stronger connection between concepts and L1 lemmas than between concepts and L2 lemmas (Kroll \& Stewart, 1994). Hence, when a concept could be prepared, more activation was sent to the respective L1 lemma than to the L2 lemma, making it easier to select the former in a switch condition. These differently weighed connections have been implemented in several language control models (Declerck et al., 2015a; Grainger et al., 2010; Schwieter \& Sunderman, 2008). 
Hence, while the study of Declerck et al. (2015a) indicates that language control could already initiate at the concept level, little to no further research has been conducted in this field. This demonstrates the pressing need for additional research into the role of the concept level during language control.

\section{The role of lemmas during language control}

Even though many models assume that language control occurs, at least partially, at the lemma level, very few studies have investigated this. Some evidence for the involvement of lemmas during language control comes from studies that investigated language switching with sentences instead of single words, since each lemma includes the syntactic information of the word, and sentence processing is assumed to occur at the lemma level (for a review on bilingual models of sentence processing, see Hartsuiker \& Pickering, 2008). Tarlowski, Wodniecka, et al. (2013), for example, asked Polish-English bilinguals to describe a scene on a picture, either in a present progressive or a present perfective phrase. Their results indicated that language switch costs can be obtained when switching between sentences (for a similar result within sentences, see Bultena, Dijkstra, \& van Hell, 2015). Furthermore, asymmetrical switch costs were obtained with progressive phrases and symmetrical switch costs with perfective phrases. From the latter finding it appears that different aspects of sentence processing, and thus lemma processing, can have an impact on language switching.

Declerck and Philipp (2015a) also found evidence for the influence of sentence processing on language switching. Their results indicated no switch costs with the SBLS paradigm when German-English bilinguals produced words in sentences that were syntactically correct when translating it word-to-word to the other language (for other studies that found no switch costs with sentences, see also Dussias, 2003; Gullifer, Kroll, \& Dussias, 2013; Ibáñez, Macizo, \& Bajo, 2010; Zhang et al., 2014). On the other hand, substantial switch costs were still observed in scrambled sentences or sentences that were not syntactically correct when translating it word-to-word. These results further support the influence of syntactic sentence information on language switching.

Taken together, while the present findings are encouraging, due to the small amount of studies it is hard to come to any final conclusions. More research in this theoretically important field of language control should help our understanding of the role of lemmas.

\section{The role of phonology during language control}

Whereas most models assume a crucial role for the concept or lemma level during language control, a relatively large amount of studies observed evidence for a role of phonology during language control (see also Gollan et al., 2014b, for corroborative evidence with bilingual language intrusions). Recent evidence comes from studies that investigated the effect of language switching on accents. Goldrick, Runnqvist, and Costa (2014) observed that Spanish-English bilinguals produced English words with a more pronounced Spanish accent in switch trials than in repetition trials. Yet, no such effect was observed for English. Olson (2013), on the other hand, observed an opposite pattern, with Spanish-English bilinguals producing Spanish words with a more pronounced English accent in switch trials than in repetition trials, whereas no such effect was found for English words. Regardless of the specific pattern, a more pronounced accent of the non-target language in switch trials clearly indicates that phonological processing is affected by language switching.

The earliest studies that manipulated characteristics of phonology in language switching tasks were studies that investigated cognate status. ${ }^{2}$ Although studies exploring the role of cognates on switch costs found an effect, a discrepancy in the switch cost pattern has been observed between studies that implemented cognates or noncognates in individual blocks (e.g., Declerck et al., 2012) compared against studies that used cognates and non-cognates in the same block (e.g., Christoffels et al., 2007; Filippi et al., 2014; Thomas \& Allport, 2000). In the former, switch costs are smaller with cognates, whereas in the latter switch costs are larger for cognates relative to noncognates.

Interestingly, Broersma (2011) found that switch trial interference was smaller after cognates than after non-cognates. This would explain the smaller switch costs with cognates than noncognates when they are both implemented in separate blocks (i.e., Declerck et al., 2012) as a persisting effect on the phonological level (e.g., persisting activation/inhibition). The larger switch costs when cognates and noncognates are presented in the same blocks could then be explained with withintrial control processes.

Whereas the previous studies mainly manipulated phonological features within trials, Declerck and Philipp (2015b) investigated the effect of phonological overlap across trials. More specifically, words with the same first two phonemes as the word in the previous trial were compared against words that did not phonologically overlap with the word on the previous trial. The results showed that phonological overlap changed the switch cost asymmetry between L1 and L2. Hence, this study indicates that due to a phonological manipulation, persisting control effects were affected in language switching, providing additional support to the idea that phonological processing has an effect on language control.

\footnotetext{
${ }^{2}$ Cognates are words that have a similar etymological background in two languages. This often co-occurs with a large phonological overlap (e.g., Costa et al., 2000; Hoshino \& Kroll, 2008; Libben \& Titone, 2009).
} 
Yet, not all language switching studies find a clear effect by manipulating phonological characteristics. Declerck et al. (2013) found no switch cost difference between words that consisted solely of phonemes that occur in both languages (e.g., Bein, meaning "leg" in German) and words that contained language-specific phonemes (e.g., Katze, meaning "cat" in German). This study seems to indicate that differences in phonological aspects of the stimulus words (i.e., language-specific vs. language-unspecific phonemes) do not always have an effect on language control in language switching. It should be noted, however, that there was a numerical difference due to language-specific phonemes in L2 trials: The data showed larger L2 switch costs for words with language-specific phonemes (switch costs: $80 \mathrm{~ms}$ ), relative to words without language-specific phonemes (switch costs: $48 \mathrm{~ms}$ ). Hence, even in this study it appears that there is some indication for a role of phonology during language control.

There are several interpretations of these phonological studies: Some assume an indirect effect of the phonological level on language control at the lemma level (Declerck \& Philipp, 2015b; Goldrick et al., 2014), whereas others assume that language control, next to the lemma level, also occurs at the phonology level (Olson, 2013). Goldrick et al. (2014) proposed that the difference in lemma activation, caused by language control in favor of the target language, spills over into the respective phonemes and thus allows for differences in phonology. Declerck and Philipp (2015), on the other hand, argued that there could be phonological feedback loops from the phonological representations back to the lemmas (see also, e.g., Bernolet, Hartsuiker, \& Pickering, 2012; Costa, Roelstrate, \& Hartsuiker, 2006; Dell, 1988). This would entail that the activation of lemmas would be influenced by phonology. In turn, language control at the lemma level would be influenced by phonology.

Despite the discussion as to whether the phonological level plays a direct or indirect role in language control, the consensus seems to be that the phonology level plays an important role during language control. Further research into this area of language switching should help us narrow down the exact role.

\section{The role of orthographical processing during language control}

Whereas the previous section indicates that there is evidence for a role of phonology during production-based language control, there is also some evidence for a role of orthography during comprehension-based language control. In an early comprehension study, Grainger and Beauvillain (1987) implemented a lexical decision task, in which English-French bilinguals had to respond with "yes" if a string of letters constituted a word, in mixed and pure language blocks. They found mixing costs, but only when the orthography of the words was not unique for either English or French words. Yet, some researchers (Orfanidou \& Sumner, 2005; Thomas \& Allport, 2000) have indicated that the abolishment of mixing costs might have been due to a lack of nonwords that contained language-specific orthography. Hence, simply orthographic information could have been used to respond without any need for lexical recognition. This was confirmed for switch costs with English-French bilinguals (Thomas \& Allport, 2000) and with Greek-English bilinguals (Orfinadou \& Sumner, 2005). However, with the latter, this was only the case when words with language-specific orthography were presented in the same blocks as words with languageunspecific orthography.

Orfinadou and Sumner (2005) proposed another problem with investigating language-specific vs. language-unspecific orthography: If words are language-specific due to orthography, they could be considered more univalent (i.e., specific to one language), whereas words that contain mainly languageunspecific orthography could be considered more bivalent (i.e., possible in both languages). In turn, the task switching literature provides compelling evidence that bivalency results in larger switch costs (see, e.g., Kiesel et al., 2010), because more than one response is possible and thus both languages become activated which increases language interference.

In sum, the evidence for an influence of orthography during comprehension-based language switching is not straightforward, as the results could be explained by other effects. Accordingly, we are not entirely sure about the role of orthography during language control at this point in time.

\section{Processing stages outside of language processing}

Thus far, we have solely discussed processing stages inside of language processing, which is along the lines of models that assume that language control occurs mainly within language processing (e.g., modified ICM and BIA-d). However, other models assume that some control processes occur outside language processing (e.g., ICM and BIA+). This typically means that language control is part of general cognitive control (for a recent review, see Valian, 2015). In the framework of the ICM, for example, this is represented by control processes between language schemas.

Evidence for such a claim could be derived by comparing language switching results with those obtained in task switching, the latter being a related field of nonlinguistic cognitive control (for reviews, see Kiesel et al., 2010; Vandierendonck, Liefooghe, \& Verbruggen, 2010). Interestingly, all major measures (i.e., switch costs, mixing costs, $n-2$ repetition costs, asymmetrical costs, and preparation effects) can be found in both the language switching and task switching literature. Hence, there might be some overlap between language switching and task switching or, to put it in more theoretical terms, between language control and more 
general cognitive control. This assumption has also been investigated by contrasting findings of language switching with those of task switching within the same study.

Some studies have looked into a possible overlap of language switching and task switching across age. Calabria et al. (2015) found an increase of switch costs with age during task switching (color/shape decision), but not during language switching (picture naming in L1/L2) when testing CatalanSpanish bilinguals. Weissberger et al. (2012) observed an increase of task mixing cost (color/shape decision) with increasing age when testing English-Spanish bilinguals, whereas task switch costs did not. With respect to language switching (digit naming in L1/L2), both mixing costs (see also Hernandez \& Kohnert, 1999, 2015) and switch costs (see also Gollan \& Ferreira, 2009) increased with age. In summary, these aging studies seem to indicate little overlap between language and task switching.

A similar conclusion was derived with a training study using Hebrew-English, Mandarin-English, and SpanishEnglish bilinguals (Prior \& Gollan, 2013). Whereas previous studies have shown that task switching performance can improve with training (e.g., Kray \& Lindenberger, 2000; Weissberger et al., 2012), Prior and Gollan (2013) looked into whether training either language switching (digit naming in L1/L2) or task switching (color/shape decision) would result in benefits of the other switching task. Their results indicated that with a limited amount of task switching training (two blocks of 80 trials), L2 mixing costs could be decreased. However, L1 mixing costs and L1 and L2 switch costs were unaffected. Similarly, no transfer of language switching training effects were observed on task switching.

On the other hand, Prior and Gollan (2011) found that bilinguals who switched often in daily life (SpanishEnglish) had not just smaller language switch costs, but also smaller task switch costs than bilinguals who do not often have to switch between languages (Mandarin-English). Similar results with respect to decreased task switch costs (Barac \& Bialystok, 2012; Prior \& MacWhinney, 2010) and task mixing costs (Wiseheart, Viswanathan, \& Bialystok, 2015) were found between bilinguals and monolinguals. These results indicate that long-term language switching training can have a substantial influence on task switching and thus indicates that there is an apparent link between the two switching tasks. Yet, not all studies found smaller task switch costs for bilinguals than monolinguals (e.g., Hernández, Martin, Barceló, \& Costa, 2013; Paap \& Greenberg, 2013; Wiseheart et al., 2015).

Several studies have also investigated the relationship between language switching and task switching by looking at correlations (Calabria et al., 2011, 2015; Gollan, Kleinman, et al., 2014; Klecha, 2013; Prior \& Gollan, 2013). As can be seen in Table 1, most of these studies have found little evidence for a relationship between language switch costs and task switch costs. Yet, there are some studies that did find some overlap between markers of language and task switching. Prior and Gollan (2013), for example, found a significant relationship between language and task mixing costs.

While some similarities have been observed, from this literature overview it seems that there are quite some differences between language switching and task switching, even though they are very similar on the surface. These differences could be due to the methodology implemented in prior studies. Gollan, Kleinman, et al. (2014) have argued that by using different response modalities (vocal modality with language switching and manual modality with task switching) in studies that investigate the link between language and task switching an additional difference is introduced, which could lead to additional differences between language and task switch costs. To counter this, Gollan and colleagues used vocal responses in both language and task switching tasks, and found significant and substantial correlations between L1 switch costs and task switch costs. Hence, some of the lack of overlap could be due to the tasks that have been used so far.

Other differences could also have concealed the actual overlap between language and task switching. These differences consist of using different stimuli (e.g., digits vs. pictures), using different tasks (naming in language switching and categorizing in task switching), and/or implementing a different amount of response possibilities (there is typically a larger amount of possible responses during language switching than task switching).

\section{Multiple loci of language control}

The sometimes complex pattern of results across studies that has been shown in the previous sections could be due to language control occurring at not one, but several loci (Bobb \& Wodniecka, 2013; Gollan, Schotter, et al., 2014; Kroll et al., 2006). This idea is in line with most language control models (e.g., Declerck et al., 2015a; Dijkstra \& van Heuven, 2002; Green, 1998; Schwieter \& Sunderman, 2008). ${ }^{3}$

The idea of a two-stage language control process during language production, as suggested by Green (1998), has been investigated by Declerck et al. (2015a). By implementing different variants of the SBLS paradigm, the predictability of the language sequence, concept sequence, or both were manipulated. Consequently, language-based language control, concept-based language control, and lemma-based language control (i.e., combination of language and concept) were investigated. The results showed that German-English bilinguals instigated smaller switch costs when both the language

\footnotetext{
${ }^{3}$ Interesting to note is that several multistage models have also been proposed to explain task switching measures (e.g., Rogers \& Monsell, 1995; Rubinstein, Meyer, \& Evans, 2001). These models assume that control processes occur both prior and post stimulus presentation, which is similar to most language control models.
} 
Table 1 Overview of studies that investigated the correlations between language switching and task switching with respect to overall switch costs and/or mixing costs

\begin{tabular}{lll}
\hline Studies & Switch costs & Mixing costs \\
\hline Calabria et al. (2011) & $r(28)=.26(p=.18)$ & NA \\
Calabria et al. (2015) & $r(60)=.04(p=.75)$ & NA \\
Klecha (2013) & $r(22)=.37(p=.09)$ & NA \\
Prior and Gollan (2013) & $r(104)=.01(p=.92)$ & $r(104)=.45(p<.01)$ \\
\hline
\end{tabular}

$N A$ not available

sequence and concept sequence were predictable than when only one of these sequences was predictable, and thus provided evidence for lemma-based language control. However, no overall switch cost difference was found when only the language sequence or concept sequence (yet there was a language-based switch cost difference due to concept predictability, see above) were predictable than when neither sequence was predictable.

These results indicate that language control occurs after the specific lemma is known. The authors extrapolated from this data that language control can occur at the lemma level and between language nodes, since the latter only occurs after concepts have activated their corresponding lemmas. Though, the data would also be in line with language control solely occurring between lemmas, which entails that little direct evidence has been provided for multiple loci of language control.

Other studies have also investigated language preparation by manipulating the cue-to-stimulus interval. While some of these studies have also found no language preparation benefit on switch costs (Philipp et al., 2007), others have (Costa \& Santesteban, 2004; Fink \& Goldrick, 2015). Moreover, n-2 language repetition costs have consistently shown a language preparation benefit (Guo et al., 2013a; Philipp et al., 2007). So, in contrast with Declerck et al. (2015a), other studies did find a language preparation effect on different costs and thus evidence for language-specific control processes. Consequently, we should not rule out the idea that language control occurs between languages and between lemmas, as suggested by Green (1998). Put differently, language control could occur at multiple processing stages.

\section{Implications}

Our overview indicates that there are still many gaps in our current knowledge of where language control occurs and what the specific roles of different processing stages during this process are. Yet, it also becomes clear that there might be more than one processing stage involved during language control.
To account for the involvement of multiple processing stages, we propose two distinct language control models. The first model would be an interconnected process that feeds back to the lemma level (cf. Declerck \& Philipp, 2015b). This language control model would comply with most existing language control models that assume that language control mainly occurs at the lemma level (e.g., Declerck et al., 2015a; Grainger et al., 2010; Green, 1998). The involvement of the other language levels would be indirect, as they influence the activation of these lemmas and thus the bilingual selection process. The problem with this model is the small amount of evidence that language control occurs at the lemma level (see the section "The role of lemmas during language control").

Another explanation for the complex pattern of results across studies that we reviewed here could be that language control occurs at not one, but several loci. A similar account has been proposed by Bobb and Wodniecka (2013), Gollan, Schotter, and colleagues (2014), and Kroll and colleagues (2006). Kroll et al. (2006), for example, assumed that the involvement of specific loci would rely on factors such as language proficiency, task demands and the activity of the nontarget language. Hence, it could be that some language switching studies find evidence for a certain locus of language control, whereas another do not, due to differences in one or more of these three characteristics.

\section{Conclusions}

In the current review article, we discussed how and where language control occurs during language switching. Based on the current literature, we acknowledge that inhibition occurs during language switching. However, it could be that next to inhibition other processes, such as activation, also play a significant role during language switching. This would leave a much broader array of explanations for results, which seems to be in line with the data. Yet, more research is needed to investigate the role of activation and other possible processes (e.g., passive decay) during language control, since these have been mostly neglected in past research.

With respect to where language control occurs, there is (some) evidence for a role of the concept level, lemma level, and phonology, and possibly even for orthography and a processing stage outside of language processing. To account for such a complex language control process, two models have been proposed: The first is an interconnected system that feeds back to the lemmas, where language control would then occur, whereas the second model would rely on multiple loci. One important issue for future research would be to investigate the relationship between these different levels and their specific involvement during language switching in particular and language control in general. 
Authors' Note We would like to thank two anonymous reviewers for their helpful comments on an earlier version of this article.

\section{References}

Abutalebi, J., \& Green, D. W. (2007). Bilingual language production: The neurocognition of language representation and control. Journal of Neurolinguistics, 20, 242-275.

Abutalebi, J., \& Green, D. W. (2008). Control mechanisms in bilingual language production: Neural evidence from language switching studies. Language and Cognitive Processes, 23, 557-582.

Abutalebi, J., Miozzo, A., \& Cappa, S. F. (2000). Do subcortical structures control 'language selection' in polyglots? Evidence from pathological language mixing. Neurocase, 6, 51-56.

Barac, R., \& Bialystok, E. (2012). Bilingual effects on cognitive and linguistic development: Role of language, cultural background, and education. Child development, 83, 413-422.

Bernolet, S., Hartsuiker, R. J., \& Pickering, M. J. (2012). Effects of phonological feedback on the selection of syntax: Evidence from between-language syntactic priming. Bilingualism: Language and Cognition, 15, 503-516.

Bobb, S. C., \& Wodniecka, Z. (2013). Language switching in picture naming: What asymmetric switch costs (do not) tell us about inhibition in bilingual speech planning. Journal of Cognitive Psychology, 25, 568-585.

Broersma, M. (2011). Triggered code-switching: Evidence from picture naming experiments. In M. S. Schmid \& W. Lowie (Eds.), Modeling bilingualism: From structure to chaos: In honor of Kees de Bot (pp. 37-58). Amsterdam, The Netherlands: Benjamins.

Bultena, S., Dijkstra, T., \& van Hell, J. G. (2015). Switch cost modulations in bilingual sentence processing: Evidence from shadowing. Language, Cognition and Neuroscience, 30, 586-605.

Calabria, M., Branzi, F. M., Marne, P., Hernández, M., \& Costa, A. (2015). Age-related effects over bilingual language control and executive control. Bilingualism: Language and Cognition, 18, 65-78.

Calabria, M., Hernández, M., Branzi, F. M., \& Costa, A. (2011). Qualitative differences between bilingual language control and executive control: Evidence from task-switching. Frontiers in Psychology, 2, 399.

Calabria, M., Marne, P., Romero-Pinel, L., Juncadella, M., \& Costa, A. (2014). Losing control of your languages: A case study. Cognitive neuropsychology, 31, 266-286.

Chauncey, K., Grainger, J., \& Holcomb, P. J. (2011). The role of subjective frequency in language switching: An ERP investigation using masked priming. Memory and Cognition, 39, 291-303.

Christoffels, I. K., Firk, C., \& Schiller, N. O. (2007). Bilingual language control: An event-related brain potential study. Brain Research, 1147, 192-208.

Costa, A., Caramazza, A., \& Sebastián-Gallés, N. (2000). The cognate facilitation effect: Implications for models of lexical access. Journal of Experimental Psychology: Learning, Memory, and Cognition, 26, $1283-1296$

Costa, A., Miozzo, M., \& Caramazza, A. (1999). Lexical selection in bilinguals: Do words in the bilingual's two lexicons compete for selection? Journal of Memory, and Language, 41, 365-397.

Costa, A., Roelstraete, B., \& Hartsuiker, R. J. (2006). The lexical bias effect in bilingual speech production: Evidence for feedback between lexical and sublexical levels across languages. Psychonomic Bulletin \& Review, 13, 972-977.

Costa, A., \& Santesteban, M. (2004). Lexical access in bilingual speech production: Evidence from language switching in highly proficient bilinguals and L2 learners. Journal of Memory, and Language, 50, 491-511.
Costa, A., Santesteban, M., \& Ivanova, I. (2006b). How do highly proficient bilinguals control their lexicalization process? Inhibitory and language-specific selection mechanisms are both functional. Journal of Experimental Psychology: Learning, Memory, and Cognition, 32, 1057-1074.

de Bruin, A., Roelofs, A., Dijkstra, T., \& FitzPatrick, I. (2014). Domaingeneral inhibition areas of the brain are involved in language switching: FMRI evidence from trilingual speakers. NeuroImage, 90, 348-359.

Declerck, M., Koch, I., \& Philipp, A. M. (2012). Digits vs. pictures: The influence of stimulus type on language switching. Bilingualism: Language and Cognition, 15, 896-904.

Declerck, M., Koch, I., \& Philipp, A. M. (2015a). The minimum requirements of language control: Evidence from sequential predictability effects in language switching. Journal of Experimental Psychology: Learning, Memory, and Cognition, 41, 377-394.

Declerck, M., \& Philipp, A. M. (2015a). A sentence to remember: Instructed language switching in sentences. Cognition, 137, 166173.

Declerck, M., \& Philipp, A. M. (2015b). The unusual suspect: Influence of phonological overlap on language control. Bilingualism: Language and Cognition.

Declerck, M., Philipp, A. M., \& Koch, I. (2013). Bilingual control: Sequential memory in language switching. Journal of Experimental Psychology: Learning, Memory, and Cognition, 39, 1793-1806.

Declerck, M., Stephan, D. N., Koch, I., \& Philipp, A. M. (2015b). The other modality: Auditory stimuli in language switching. Journal of Cognitive Psychology (in press)

Declerck, M., Thoma, A. M., Koch, I., \& Philipp, A. M. (2015c). Highly proficient bilinguals implement inhibition: Evidence from n-2 language repetition costs when switching between three languages (in press)

Dell, G. S. (1988). The retrieval of phonological forms in production: Tests of predictions from a connectionist model. Journal of Memory and Language, 27, 124-142.

Dijkstra, T., \& Van Heuven, W. J. (2002). The architecture of the bilingual word recognition system: From identification to decision. Bilingualism: Language and Cognition, 5, 175-197.

Dussias, P. E. (2003). Syntactic ambiguity resolution in second language learners: Some effects of bilinguality on L1 and L2 processing strategies. Studies in Second Language Acquisition, 25, 529-557.

Festman, J., Rodriguez-Fornells, A., \& Münte, T. F. (2010). Individual differences in control of language interference in late bilinguals are mainly related to general executive abilities. Behavioral and Brain Functions, 6, 5.

Filippi, R., Karaminis, T., \& Thomas, M. S. C. (2014). Bilingual language switching in production: Empirical and computational studies. Bilingualism: Language and Cognition, 17, 294-315.

Fink, A., \& Goldrick, M. (2015). Pervasive benefits of preparation in language switching. Psychonomic Bulletin \& Review.

Finkbeiner, M., Almeida, J., Janssen, N., \& Caramazza, A. (2006). Lexical selection in bilingual speech production does not involve language suppression. Journal of Experimental Psychology: Learning, Memory, and Cognition, 32, 1075-1089.

Goldrick, M., Runnqvist, E., \& Costa, A. (2014). Language switching makes pronunciation less nativelike. Psychological Science, 25, 1031-1036.

Gollan, T. H., \& Ferreira, V. S. (2009). Should I stay or should I switch? A cost-benefit analysis of voluntary language switching in young and aging bilinguals. Journal of Experimental Psychology: Learning, Memory, and Cognition, 35, 640-665.

Gollan, T. H., Kleinman, D., \& Wierenga, C. E. (2014a). What's easier: Doing what you want, or being told what to do? Cued versus voluntary language and task switching. Journal of Experimental Psychology: General, 143, 2167-2195. 
Gollan, T. H., Sandoval, T., \& Salmon, D. P. (2011). Cross-language intrusion errors in aging bilinguals reveal the link between executive control and language selection. Psychological Science, 22, 11551164.

Gollan, T. H., Schotter, E. R., Gomez, J., Murillo, M., \& Rayner, K. (2014b). Multiple levels of bilingual language control: Evidence from language intrusions in reading aloud. Psychological science, $25,585-595$.

Grainger, J., \& Beauvillain, C. (1987). Language blocking and lexical access in bilinguals. Quarterly Journal of Experimental Psychology, 39, 295-319.

Grainger, J., \& Dijkstra, T. (1992). On the representation and use of language information in bilinguals. In R. J. Harris (Ed.), Cognitive processing in bilinguals. Amsterdam, The Netherlands: North Holland.

Grainger, J., \& Holcomb, P. J. (2009). Watching the Word Go by: On the Time-course of Component Processes in Visual Word Recognition. Language and Linguistics Compass, 3, 128-156.

Grainger, J., Midgley, K. J., \& Holcomb, P. J. (2010). Re-thinking the bilingual interactive-activation model from a developmental perspective (BIA-d). In M. Kail \& M. Hickman (Eds.), Language acquisition across linguistic and cognitive systems (pp. 267-284). Philadelphia, PA: John Benjamins.

Green, D. W. (1998). Mental control of the bilingual lexico-semantic system. Bilingualism: Language and Cognition, 1, 213-229.

Gullifer, J. W., Kroll, J. F., \& Dussias, P. E. (2013). When language switching has no apparent cost: Lexical access in sentence context. Frontiers in Psychology, 4, 278.

Guo, T., Liu, F., Chen, B., \& Li, S. (2013a). Inhibition of non-target languages in multilingual word production: Evidence from Uighur-Chinese-English trilinguals. Acta Psychologica, 143, 277283.

Guo, T., Ma, F., \& Liu, F. (2013b). An ERP study of inhibition of nontarget languages in trilingual word production. Brain and Language, 127, 12-20.

Hanulová, J., Davidson, D. J., \& Indefrey, P. (2011). Where does the delay in L2 picture naming come from? Psycholinguistic and neurocognitive evidence on second language word production. Language and Cognitive Processes, 26, 902-934.

Hartsuiker, R. J., \& Pickering, M. J. (2008). Language integration in bilingual sentence production. Acta Psychologica, 128, 479-489.

Hermans, D., Bongaerts, T., De Bot, K., \& Schreuder, R. (1998). Producing words in a foreign language: Can speakers prevent interference from their first language? Bilingualism: Language and Cognition, 1, 213-229.

Hernandez, A. E., Dapretto, M., Mazziotta, J., \& Bookheimer, S. (2001). Language switching and language representation in SpanishEnglish bilinguals: An fMRI study. NeuroImage, 14, 510-520.

Hernandez, A. E., \& Kohnert, K. J. (1999). Aging and language switching in bilinguals. Aging Neuropsychology and Cognition, 6 , 69-83.

Hernandez, A. E., \& Kohnert, K. J. (2015). Investigations into the locus of language- switching costs in older adult bilinguals. Bilingualism: Language and Cognition, 18, 51-64.

Hernández, M., Martin, C. D., Barceló, F., \& Costa, A. (2013). Where is the bilingual advantage in task-switching? Journal of Memory and Language, 69, 257-276.

Hoshino, N., \& Kroll, J. F. (2008). Cognate effects in picture naming: Does cross-language activation survive a change of script? Cognition, 106, 501-511.

Hosoda, C., Hanakawa, T., Nariai, T., Ohno, K., \& Honda, M. (2012). Neural mechanisms of language switch. Journal of Neurolinguistics, $25,44-61$.

Ibáñez, A., Macizo, P., \& Bajo, M. (2010). Language access and language selection in professional translators. Acta Psychologica, 135, 257 266
Jackson, G. M., Swainson, R., Cunnington, R., \& Jackson, S. R. (2001). ERP correlates of executive control during repeated languageswitching. Bilingualism: Language and Cognition, 4, 169-178.

Jackson, G. M., Swainson, R., Mullin, A., Cunnington, R., \& Jackson, S. R. (2004). ERP correlates of a receptive language-switching task. The Quarterly Journal of Experimental Psychology, 57, 223-240.

Jia, G., Kohnert, K., Collado, J., \& Aquino-Garcia, F. (2006). Action naming in Spanish and English by sequential bilingual children and adolescents. Journal of Speech, Language, and Hearing Research, 48, 1-12.

Jin, Z. L., Zhang, J. X., \& Li, L. (2014). Endogenous language control in Chinese-English switching: An event-related potentials study. Neuroscience bulletin, 30, 461-468.

Kiesel, A., Wendt, M., Jost, K., Steinhauser, M., Falkenstein, M., Philipp, A. M., \& Koch, I. (2010). Control and interference in task switching: A review. Psychological Bulletin, 136, 849-874.

Klecha, A. (2013). Language and task switching in Polish-English bilinguals. Psychology of Language and Communication, 17, 17-36.

Koch, I., Gade, M., Schuch, S., \& Philipp, A. M. (2010). The role of inhibition in task switching: A review. Psychonomic Bulletin \& Review, 17, 1-14.

Kohnert, K. (2002). Picture naming in early sequential bilinguals: A 1year follow-up. Journal of Speech, Language, and Hearing Research, 45, 759-771.

Kohnert, K. J., Bates, E., \& Hernandez, A. E. (1999). Balancing bilinguals: Lexical-semantic production and cognitive processing in children learning Spanish and English. Journal of Speech, Language, and Hearing Research, 42, 1400-1413.

Kolers, P. A. (1966). Reading and talking bilingually. The American Journal of Psychology, 357-376.

Kray, J., \& Lindenberger, U. (2000). Adult age differences in task switching. Psychology and aging, 15, 126.

Kroll, J. F., Bobb, S. C., Misra, M., \& Guo, T. (2008). Language selection in bilingual speech: Evidence for inhibitory processes. Acta Psychologica, 128, 416-430.

Kroll, J. F., Bobb, S. C., \& Wodniecka, Z. (2006). Language selectivity is the exception, not the rule: Arguments against a fixed locus of language selection in bilingual speech. Bilingualism: Language and Cognition, 9, 119-135.

Kroll, J. F., \& Stewart, E. (1994). Category interference in translation and picture naming: Evidence for asymmetric connections between bilingual memory representations. Journal of Memory and Language, $33,149-174$

La Heij, W. (2005). Selection processes in monolingual and bilingual lexical access. In J. F. Kroll \& A. M. B. de Groot (Eds.), Handbook of bilingualism: Psycholinguistic approaches (pp. 289307). Oxford, England: Oxford University Press.

Levelt, W. J. M., Roelofs, A., \& Meyer, A. S. (1999). A theory of lexical access in speech production. Behavioral and Brain Sciences, 22, 1 75

Libben, M., \& Titone, D. (2009). Bilingual language processing in context: Evidence from eye movement recordings during reading. Journal of Experimental Psychology: Learning, Memory, and Cognition, 35, 381-390.

Linck, J. A., Schwieter, J. W., \& Sunderman, G. (2012). Inhibitory control predicts language switching performance in trilingual speech production. Bilingualism: Language and Cognition, 15, 651-662.

Liu, H., Rossi, S., Zhou, H., \& Chen, B. (2014). Electrophysiological evidence for domain- general inhibitory control during bilingual language switching. PloS one, 9, e110887.

Los, S. A. (1996). On the origin of mixing costs: Exploring information processing in pure and mixed blocks and trials. Acta Psychologica, 94, 145-188.

Luk, G., Green, D. W., Abutalebi, J., \& Grady, C. (2012). Cognitive control for language switching in bilinguals: A quantitative meta- 
analysis of functional neuroimaging studies. Language and Cognitive Processes, 27, 1479-1488.

Macizo, P., Bajo, T., \& Paolieri, D. (2012). Language switching and language competition. Second Language Research, 28, 131-149.

Macnamara, J., Krauthammer, M., \& Bolgar, M. (1968). Language switching in bilinguals as a function of stimulus and response uncertainty. Journal of Experimental Psychology, 78, 208-215.

Macnamara, J., \& Kushnir, S. (1971). Linguistic independence in bilinguals: The input switch. Journal of Verbal Learning and Verbal Behavior, 10, 480-487.

Martin, C. D., Strijkers, K., Santesteban, M., Escera, C., Hartsuiker, R. J., \& Costa, A. (2013). The impact of early bilingualism on controlling a language learned late: An ERP study. Frontiers in Psychology, 4, 815.

Meuter, R. F. I., \& Allport, A. (1999). Bilingual language switching in naming: Asymmetrical costs of language selection. Journal of Memory and Language, 40, 25-40.

Olson, D. J. (2013). Bilingual language switching and selection at the phonetic level: Asymmetrical transfer in VOT production. Journal of Phonetics, 41, 407-420.

Orfanidou, E., \& Sumner, P. (2005). Language switching and the effects of orthographic specificity and response repetition. Memory \& Cognition, 33, 355-369.

Paap, K. R., \& Greenberg, Z. I. (2013). There is no coherent evidence for a bilingual advantage in executive processing. Cognitive Psychology, 66, 232-258.

Peeters, D., Runnqvist, E., Bertrand, D., \& Grainger, J. (2014). Asymmetrical switch costs in bilingual language production induced by reading words. Journal of Experimental Psychology: Learning, Memory, and Cognition, 40, 284-292.

Philipp, A. M., Gade, M., \& Koch, I. (2007). Inhibitory processes in language switching: Evidence from switching language-defined response sets. European Journal of Cognitive Psychology, 19, 395416.

Philipp, A. M., \& Koch, I. (2009). Inhibition in language switching: What is inhibited when switching between languages in naming tasks? Journal of Experimental Psychology: Learning, Memory, and Cognition, 35, 1187-1195.

Plaut, D. C., McClelland, J. L., Seidenberg, M. S., \& Patterson, K. (1996). Understanding normal and impaired word reading: Computational principles in quasi-regular domains. Psychological review, 103, 56115.

Poulisse, N., \& Bongaerts, T. (1994). First language use in second language production. Applied Linguistics, 15, 36-57.

Price, C. J., Green, D. W., \& von Studnitz, R. (1999). A functional imaging study of translation and language switching. Brain, 122, $2221-2235$

Prior, A., \& Gollan, T. H. (2011). Good language-switchers are good taskswitchers: Evidence from Spanish-English and Mandarin-English bilinguals. Journal of the International Neuropsychological Society, 17, 682-691.

Prior, A., \& Gollan, T. H. (2013). The elusive link between language control and executive control: A case of limited transfer. Journal of Cognitive Psychology, 25, 622-645.
Prior, A., \& MacWhinney, B. (2010). A bilingual advantage in task switching. Bilingualism: Language and Cognition, 13, 253-262.

Roelofs, A. (1998). Lemma selection without inhibition of languages in bilingual speakers. Bilingualism: Language and Cognition, 1, 94 95.

Rogers, R. D., \& Monsell, S. (1995). Costs of a predictable switch between simple cognitive tasks. Journal of Experimental Psychology: General, 124, 207-231.

Rubinstein, J. S., Meyer, D. E., \& Evans, J. E. (2001). Executive control of cognitive processes in task switching. Journal of Experimental Psychology: Human Perception and Performance, 27, 763-797.

Runnqvist, E., Strijkers, K., Sadat, J., \& Costa, A. (2011). On the temporal and functional origin of $\mathrm{L} 2$ disadvantages in speech production: A critical review. Frontiers in Psychology, 2, 379.

Schwieter, J. W., \& Sunderman, G. (2008). Language switching in bilingual speech production: In search of the language-specific selection mechanism. The Mental Lexicon, 3, 214-238.

Simon, J. R. (1969). Reactions toward the source of stimulation. Journal of experimental psychology, 81, 174-176.

Tarlowski, A., Wodniecka, Z., \& Marzecová, A. (2013). Language switching in the production of phrases. Journal of Psycholinguistic Research, 42, 103-118.

Thomas, M. S. C., \& Allport, A. (2000). Language switching costs in bilingual visual word recognition. Journal of Memory and Language, 43, 44-66.

Valian, V. (2015). Bilingualism and cognition: A focus on mechanisms. Bilingualism: Language and Cognition, 18, 47-50.

Vandierendonck, A., Liefooghe, B., \& Verbruggen, F. (2010). Task switching: Interplay of reconfiguration and interference control. Psychological Bulletin, 136, 601-626.

Verhoef, K. M. W., Roelofs, A., \& Chwilla, D. J. (2009). Role of inhibition in language switching: Evidence from event-related brain potentials in overt picture naming. Cognition, 110, 84-99.

Verhoef, K. M. W., Roelofs, A., \& Chwilla, D. J. (2010). Electrophysiological evidence for endogenous control of attention in switching between languages in overt picture naming. Journal of Cognitive Neuroscience, 22, 1832-1843.

von Studnitz, R. E., \& Green, D. W. (1997). Lexical decision and language switching. International Journal of Bilingualism, 1, 3-24.

Wang, Y., Kuhl, P. K., Chen, C., \& Dong, Q. (2009). Sustained and transient language control in the bilingual brain. NeuroImage, 47, 414-422.

Weissberger, G. H., Wierenga, C. E., Bondi, M. W., \& Gollan, T. H. (2012). Partially over-lapping mechanisms of language and task control in young and older bilinguals. Psychology and Aging, 27, 959-974.

Wiseheart, M., Viswanathan, M., \& Bialystok, E. (2015). Flexibility in task switching by monolinguals and bilinguals. Bilingualism: Language and Cognition.

Zhang, Y., Huang, P., Song, Z., Fang, L., Shen, T., Li, Y., . . Peng, X. (2014). In-context language control with production tasks in bilinguals: An fMRI study. Brain Research, 1585, 131-140. 